\title{
ANTÍTESIS CHILENAS SOBRE UNIVERSIDAD, LIBERTAD Y PLURALISMO*
}

\author{
Enzo Solari \\ Pontificia Universidad Católica de Valparaiso
}

\begin{abstract}
Resumen: De acuerdo al autor, en Chile se han erigido dos tesis amenazantes para la institución universitaria. Una es la tesis deflacionaria, que impugna la necesidad de justificar la idea y de sofisticar los estándares institucionales de la universidad, por lo cual centros de formación técnica e institutos profesionales bien podrían ser contados como universidades. La otra es la tesis del pluralismo restringido, según la cual las universidades podrían tener un ideario tan fuerte que les permita limitar decididamente su pluralismo, el cual
\end{abstract}

Enzo Solari. Abogado por la Pontificia Universidad Católica de Valparaíso (PUCV). Doctor en filosofía por la Hochschule für Philosophie/Philosophische Fakultät SJ, München, Alemania. Profesor en la Escuela de Derecho de la PUCV. Sus últimos libros son El problema de Dios según Heidegger y otros ensayos de fenomenología, religión y cristianismo (Valparaíso: Ediciones Universitarias de Valparaíso - EUV-, 2014) y Sobre la filosofia jurídica de Jorge Millas y otros ensayos iusfilosóficos, de teoría política y constitucional (Valparaíso: EUV, 2015). Email: enzo.solari@pucv.cl.

* El autor quiere señalar: "Este texto — redactado en el marco de una beca C de Stipendienwerk Lateinamerika-Deutschland otorgada a mi proyecto 'La tolerancia en Kant: supuestos epistémicos, políticos y religiosos', y de mi Fondecyt regular n. ${ }^{\circ}$ 1150686: 'Tolerancia, razón y juicio. Crítica y metafísica en la filosofía jurídica y política de Kant' - se benefició de su discusión en el coloquio permanente de filosofía del derecho y derecho penal de la Escuela de Derecho de la PUCV, en el simposio 'Concepto e institucionalización de la universidad', en el IV Congreso Nacional de Filosofía de 2015, y en el taller que bajo la misma denominación se llevó a cabo en la PUCV en enero de 2016. Además, recibió precisos y críticos comentarios por parte de Eugenio Severin y Manfred Svensson, así como de los evaluadores anónimos de Estudios Públicos". 
sólo sería necesario preservar respecto del sistema universitario en su conjunto y no al interior de cada institución. Pero si la universidad moderna (en especial si es entendida kantianamente) es aquella comunidad donde se practica la libre docencia e investigación de las ciencias, humanidades, artes y algunas profesiones, entonces en este tipo de institución será exigible que el estudio y la enseñanza se lleven a cabo en un ambiente de amplia libertad académica y robusto pluralismo intelectual. Todo lo cual, de acuerdo al autor, puede y debe ser consagrado política y jurídicamente.

Palabras Clave: universidad, libertad académica, autonomía universitaria, pluralismo, Kant.

RECIBIDO: marzo 2016; ACEPTADO: junio 2016.

\title{
CHILEAN ANTITHESES OF UNIVERSITY, FREEDOM AND PLURALISM
}

\begin{abstract}
According to the author, two theses have been constructed that are threatening the institution of the university. One is the deflationary thesis, that challenges the need to justify the idea of university and to sophisticate the university's institutional standards, so centers of technical training and professional institutes could well be considered universities. The other thesis is restricted pluralism, according to which universities might have such a strong ideology that they are decidedly able to limit their pluralism, which would only have to be preserved for the university system as a whole and not within each institution. Yet if modern university (in particular if understood according to Kant) is a community for the free practice of teaching and research in the sciences, humanities, arts and some professions, then that type of institution will be required to conduct research and to teach in an environment of ample academic freedom and robust intellectual pluralism, all of which, according to the author, can and must be established in policy and the law.
\end{abstract}

KEYwORDS: university, academic freedom, university autonomy, pluralism, Kant.

RECEIVED: March 2016; ACCEPTED: June 2016.

\footnotetext{
- i la universidad hubiera de ser un espacio donde reina la libertad - de docencia y de investigación, y donde tal autonomía académica - también administrativa y económica - exige una comunidad talentosa, diversa y plural de investigadores, docentes y discentes de ciencias, artes y humanidades —y quizá de algunas carreras técnicas y profesio-
} 
nales-, ¿hay todavía un espacio para la universidad así entendida en los tiempos que corren? La pregunta es especialmente localizable en Chile, pues entre nosotros circulan, y con cierto arraigo, al menos dos tesis que contrastan con este paradigma universitario.

Por una parte, existe la tesis deflacionaria (TD), promovida en Chile por José Joaquín Brunner, según el cual habría que admitir que la universidad contemporánea es más bien una "multiversidad" o, como dice al citar a Clark Kerr:

"una ciudad de infinita variedad"; una serie de comunidades sueltamente acopladas bajo un nombre común, una junta de gobierno y unos propósitos relacionados entre sí. Nace así un nuevo tipo de institución, decía el autor, ni pública ni privada, no enteramente del mundo ni aparte de él, una estación de servicio para todo público; en suma, una institución surgida de un imperativo histórico antes que de una elección racional entre alternativas igualmente elegantes. ${ }^{1}$ (159)

Por supuesto, la TD es deflacionaria desde el punto de vista intensional - por las (muy pocas) notas que especificarían lo universitario-, ya que extensionalmente es una tesis inflacionaria - por las (muchas) instituciones que bajo su alero podrían ser llamadas y tratadas como universidades - . La Universidad del Mar es sólo la punta de lanza de un fenómeno extendido: el de "universidades" que forman parte de la clase universitaria chilena sólo por haber satisfecho unas exigencias bastante mínimas - precisamente a lo que se alude cuando se dice de ellas que no son universidades "complejas"-.

Si en Brunner aflora esta tesis, hay que admitir que su estilo expositivo dificulta identificar las ideas precisas que cabe adscribir a la TD. Con todo, y espigando con cuidado, la TD parecería afirmar cuando menos lo que sigue: las universidades son "multiversas" porque serían

${ }^{1}$ Para esta cita y las que siguen, ver J. J. Brunner, "Ideas y fines de la universidad”, Estudios Públicos 139 (2015): 155-164. En paréntesis, el número de página citado. 
ya instituciones posmodernas respecto de las cuales no hay ideas unitarias que las justifiquen. Agrega Brunner:

No hay ninguna "idea" que las funde, justifique o pueda incluirlas a todas. Resulta imposible predicar que cada una individualmente sea un locus veritatis o que colectivamente tengan la misma razón de ser o institucionalicen por igual la conciencia de la nación o formen coherentemente un mismo tipo humano.

Incluso más: a esta altura podemos preguntarnos, igual como hace un historiador británico, por qué la universidad moderna necesitaría una "idea" fundante, en el sentido de una razón de ser o una justificación. Confiesa que le parece una cuestión misteriosa. Lo mismo me sucede a mí. (160)

Así, echando mano del vocabulario de la posmodernidad, vale decir, el del término de la justificación a partir de "grandes relatos", la TD entiende que las universidades no son sino un caso más

(...) del fenómeno de creciente instrumentalización del conocimiento en todos los ámbitos. En breve, es lo que Lyotard - padre del término tal como aquí lo empleamos- describió como el irresistible avance de la performatividad; esto es, el predominio del "criterio tecnológico" en todos los ámbitos de la cultura; el principio de la más eficiente razón entre insumo y producto; en fin, la mercantilización del conocimiento convertido en commodity. (161)

¿Es esto una mera descripción, o es también en algún sentido una evaluación del "irresistible avance de la performatividad" y de "la mercantilización del conocimiento convertido en commodity"? Como la TD en la versión de Brunner entremezcla ambas cosas, creo que se vuelve necesario distinguir. Descriptivamente, la TD dice que el "capitalismo académico" se ha expresado en políticas neoliberales que

(...) explicarían las transformaciones contemporáneas de la educación superior: diferenciación y masificación de los sistemas nacionales; aparición de nuevos proveedores privados; competencia entre organizaciones académicas por personal, recursos y prestigio; débil coordinación provista por mercados desregulados; obligación para las instituciones —incluidas las universidades es- 
tatales - de obtener una parte de sus ingresos mediante el cobro de aranceles y la venta de servicios y productos de conocimiento, y un Estado subsidiario que se limita a financiar la libre elección de oportunidades de estudio (soberanía del consumidor) y a suplir las fallas del mercado. (161)

Pero evaluativamente, la TD asegura que la idea moderna de universidad está siendo negada por estas transformaciones:

Dicho en una frase: la universidad dejaría de ser la sede de la razón y la conciencia más clara de la época para convertirse en un aparato del conocimiento útil; una máquina de desempeños eficientes y rendición de cuentas, donde toda actividad es medida y se ordena en función de la productividad y los beneficios para la economía y la sociedad. La universidad, acusan los críticos, se habría vuelto performativa; es decir, una organización ocupada en asegurar la mejor optimización de todas sus acciones.

(...) Pudiera ser verdad entonces que la universidad no necesita ya una "razón de ser", una justificación, toda vez que se ha convertido en un aparato central de la educación de masas, la certificación para el trabajo y la producción de conocimiento útil, de la cual se esperan beneficios económicos, de integración social y de difusión cultural. (162-163)

Todo lo cual lleva a la TD a concluir que, con la llegada de la universidad multiversa, posmoderna y —en sus propias palabras — neoliberal,

(...) las cuestiones que antes se abordaban especulativamente en el terreno de las grandes "ideas" se resolverían mediante arreglos pragmáticos del estilo: cuánto Estado, cuánto mercado, y mediante qué instrumentos de política socialdemócrata o neoliberal. El resto queda entregado a consideraciones de productividad y mediciones de eficiencia funcional. (163-164)

Pues bien, el problema de la TD radica precisamente en el carácter intensionalmente deflacionario de su idea universitaria. En efecto, la universidad certificadora para el trabajo, en la que el conocimiento se 
ha vuelto commodity, es institucionalmente indistinguible de un instituto profesional, incluso de un centro de formación técnica. Esto es algo que ha ocurrido peculiarmente en Chile, donde instituciones que reclaman el nombre de "universidad" funcionan más bien como centros de aprendizaje técnico o profesional. El mismo sistema chileno de acreditación universitaria, incluso después de los escándalos y venalidades de años pasados en varias universidades privadas de reciente creación, así como en el Consejo Nacional de Acreditación, tiende a confundir universidades con instituciones meramente técnico-profesionales. ¿Cómo entender si no que el número de años de acreditación se haya independizado del carácter de una institución de educación superior (puramente docente o bien compleja por el desarrollo sistemático de investigación)? De modo, por ejemplo, que para mentalidades incautas (iy para mentalidades estratégicas!) podrían casi identificarse dos universidades acreditadas por cuatro o cinco años, estando una acreditada solamente en gestión institucional y docencia de pregrado, mientras que la otra también en posgrado e investigación. Así como hay una distancia abismática ya en docencia de pregrado entre "universidades" con escasos y sobrecargados docentes estables, y universidades que sí cuentan con planteles nutridos por académicos estables y cuya ocupación docente se combina con la actividad investigadora, así también resulta difícil de digerir que según las reglas actualmente vigentes en Chile la acreditación en investigación y posgrados sea no básica y obligatoria, sino supererogatoria y opcional.

La pregunta es obvia: ¿qué idea universitaria late bajo semejantes reglas? Y la respuesta no puede sino ser sumamente rústica: ninguna, o al menos ninguna idea demasiado comprometedora desde el punto de vista del conocimiento y la verdad. Por lo mismo es que la TD tiende a razonar no en términos conceptualmente exigentes, sino en términos elementalmente cuantitativos y frecuentemente instrumentales ("cuánto Estado, cuánto mercado, y mediante qué instrumentos de política socialdemócrata o neoliberal"), pensando que las variables fundamentales de un sistema universitario serían, como argumentan con frecuencia sus promotores, las de la gobernanza (entendida sólo como la presencia o ausencia de un agente dotado de potestades exorbitantes, es decir, público o privado) y las de la fuente de financiamiento (entendida también de acuerdo con un esquema binario extraordinariamente básico: subsidios 
estatales o donaciones de privados, esto es, Estado o mercado). Por el contrario, no debiera resultar difícil admitir que hay que darle más eficaz y sofisticada gobernanza estatal ( $\mathrm{y}$ acreditación pública) al sistema universitario en Chile, así como que hay que criticar el empleo del (muy esmirriado) financiamiento como no única pero sí dominante forma de la política del Estado chileno respecto de las instituciones de tal sistema. ${ }^{2}$

Más aún, la misma tendencia instrumental es la que permitiría explicar que sus propios exponentes asuman ideas como las de la New Public Management (NPM), según las cuales los académicos universitarios - tal como los funcionarios gubernamentales - se comportan racionalmente (en el sentido de la teoría de la elección pública) y, por ende, para velar por su desempeño y eficiencia han de estar sometidos a intensos mecanismos de control y sistemas de incentivos monetarios. Mientras, dice la NPM, los administradores universitarios deben gozar de altos niveles de autonomía para ejecutar exitosamente su labor gerencial. ${ }^{3}$ Como se sabe, se multiplican los comentarios de académicos que lamentan la (a sus ojos nefasta) influencia de gerentes universitarios en el quehacer docente e investigador de académicos propiamente tales:

Un decano del viejo estilo, con la pretensión de regresar en pocos años a sus libros, su laboratorio y sus estudiantes, tendría al menos alguna capacidad para valorar de forma independiente cuán bien y qué tan responsablemente los profesores hacían su trabajo; un decano de estilo moderno no tiene otra opción que confiar en medidas sustitutivas como el número de libros y artículos publicados, quizá matizados por alguna estimación del "prestigio" de las editoriales y revistas que, en todo caso, él no puede valorar personalmente; la cantidad de ayudas económicas recibidas; y los "rankings" departamentales, que tampoco puede evaluar por sí

${ }^{2}$ Para una crítica más detallada sobre la política chilena de financiamiento universitario, ver E. Fernández, "Políticas públicas de educación superior desde 1990 hasta el presente", en La educación superior de Chile. Transformación, desarrollo y crisis, ed. A. Bernasconi (Santiago: Ediciones UC, 2015). Para una crítica (unilateral, pero saludablemente descarnada) acerca de la acreditación y la calidad universitaria en Chile, véase R. Rodríguez, "Universidad y dictadura. A propósito de la calidad universitaria”, Escrituras aneconómicas 4 (2013), https://issuu.com/ revista-escriturasaneconomicas/docs/escrituras_del_golpe.

3 Véase M. Morales, "Nueva gestión pública en Chile: orígenes y efectos", Revista de Ciencia Politica 34, n. ${ }^{\circ} 2$ (2014): 418-419. 
mismo. Muy pronto muchos profesores empezaron a internalizar estos distorsionados valores. No es sorprendente que muchos, conscientes de que el éxito de sus carreras depende ante todo de su "productividad", deleguen el grueso de sus clases de grado a sus estudiantes de posgrado, mientras ellos imparten seminarios híper especializados en el posgrado sobre aquello en lo que han estado trabajando (...). "No es sorprendente", insisto: ciertamente, hace casi un siglo Thorstein Veblen escribió el profético libro The Higher Learning in America (1919), prediciendo que los valores de gestión empresarial que las universidades estaban empezando a adoptar inevitablemente dañarían el ethos académico.

Él estaba, lamento decirlo, exactamente en lo cierto. ${ }^{4}$

Este paradigma administrativo, dicho conservadoramente, sólo sería apropiado para la gestión estatal del sistema universitario y para la administración interna de cada universidad, a condición de no perder de vista que se trata precisamente de modos de conducir instituciones básicamente docentes e investigadoras. Es frecuente (el caso de algunas universidades privadas chilenas ha llegado a ser patético) que la gerencia se independice y confunda criterios para evaluar calidad universitaria con indicadores para estimar la producción en serie de papers y porcentajes de aprobación y reprobación estudiantil. Sin embargo, la idea universitaria se venga incluso de sus manipuladores. Así, entre quienes miran con simpatía a la NPM, algunos todavía parten de la base de que la única idea justificada y justificable de universidad - también en los tiempos que corren de masificación y mutaciones institucionales en el campo universitario - es la de una institución de educación superior caracterizada siempre por la libertad de la investigación y la docencia. ${ }^{5}$

${ }^{4}$ S. Haack, "Entrevista a Susan Haack", Doxa 36 (2013): 585-586.

${ }^{5}$ A propósito de la masificación y mutación del campo universitario chileno, véase en los años sesenta, J. Millas, "La universidad: su esencia y su reforma" (1962), en Idea y defensa de la universidad (Santiago: UDP, 2012), 34 y 42; y en los años recientes, F. Atria, Derechos sociales y educación: un nuevo paradigma de lo público (Santiago: Lom, 2014), 257-324 (“la institución (...) autónoma, financiada fuera del mercado y compuesta por académicos cuya libertad está asegurada, es la que hoy ya no existe o, para decirlo en los términos un poco menos dramáticos de Neil MacCormick, está dejando de existir": 285). Fuera de Chile, véase G. Steiner, Los logócratas (Madrid: Siruela, 2006), 84, citado por J. Llovet, Adiós a la universidad. El eclipse de las humanidades, trad. por A. Fuentes (Barcelona: G. Gutenberg, 2011), 180. 
¿Y no habría que decir algo análogo del estilo gerencial y economicista con que tan lamentablemente se ha administrado el desarrollo científicotecnológico en Chile? ${ }^{6}$ Son mentalidades obedientes a la TD y a la NPM —que han permitido identificar aun en países científicamente desarrollados una significativa "mercantilización de la ciencia" - , las que por un lado ayudan a entender el precario estado de la ciencia chilena, mientras que por el otro han facilitado la existencia de universidades lucrativas o puramente técnico-docentes. En Chile, de hecho, florecen empresas lucrativas organizadas como si fueran universidades y manejadas con criterios e incentivos mercantiles (si bien disfrazados como indicadores de "eficiencia académica") por parte de sus administradores. ${ }^{8}$ En ellas, ¡de modos jurídicamente no ilícitos!, se desarrollan prácticas tan anómalas como ruinosas en materias científicas y humanísticas, una de las cuales,

${ }^{6}$ Véase a propósito de la actual crisis de Conicyt la declaración de científicos matemáticos y naturales: Varios autores, Nuestros gobiernos han elegido la ignorancia (2015), http://www.biologiachile.cl/2015/11/09/nuestros-gobiernos-hanelegido-la-ignorancia/.

${ }^{7} \mathrm{O}$ "ciencia neoliberal", como hace E. Lander, "La ciencia neoliberal", Tabula Rasa 9 (2008): 247-283. Esto, claro, requiere de precisiones y detalles que merecerían otro artículo.

${ }^{8}$ Sobre los problemas de las universidades lucrativas, véase por todos, E. Barros y A. Fontaine, "Apuntes acerca de la universidad en tiempos de conflicto", Estudios Públicos 124 (2011): 139-149; A. Fontaine, "Lucro, universidad y filantropía", Estudios Públicos 128 (2012): 157-173; y A. Fontaine, “Contra la visión fabril de la educación: ¿Universidades con fines de lucro?”, Estudios Públicos 127 (2012): 193-217. Respecto de la amenaza no por sutil menos peligrosa de la revolución gerencialista y sus presiones administrativas y económicas sobre la docencia y la investigación universitarias, véase R. Brandt, Wozu noch Universitäten? Ein Essay (Hamburg: Meiner, 2011), 15-16 y 127-166. En Chile falta por elaborarse una crítica de la nueva administración gerencialista en el gobierno y la gobernanza universitarias, sin dejar de lado los riesgos de las universidades con fines de lucro. Lo que entre nosotros predomina es la presentación entusiasta del modelo universitario gerencial y crítica de la tradición universitaria latinoamericana de autonomía y a la chilena de gobernanza y gobierno, como la de A. Bernasconi: "Government and University Autonomy: The Governance Structure of Latin American Public Institutions", en Latin America's New Knowledge Economy: Higher Education, Government, and International Collaboration, ed. J. Balán (New York: Institute for International Education, 2013); "Autonomía universitaria en el siglo XXI: nuevas formas de legitimidad ante las transformaciones del Estado y la sociedad", Páginas de Educación 7, n. ${ }^{\circ} 2$ (2014); "El gobierno de las instituciones", en el citado La educación superior de Chile, ed. Bernasconi. 
ya insinuada, es la de "universidades" que cuentan comparativamente con muy bajas tasas de profesores contratados a jornada completa. ${ }^{9} \mathrm{Y}$ es que cuando se renuncia a la justificación (a una idea o razón de ser) de la universidad es difícil no llegar a unas tesis que, como la TD, son científicamente infértiles y torpes, y por cierto argumentativamente mañosas, pues, so pretexto de neutralidad, terminan por legitimar políticas y reglas perfectamente congruentes con un sistema universitario como el chileno: excesivo, desregulado, caótico. ${ }^{10}$

Pero hay más. La TD es una de las maneras de discutir la idea de universidad entendida como comunidad académica caracterizable por la libre docencia e investigación. Hay otra forma de discutir esta idea.

3.

Se trata de la tesis del pluralismo universitario restringido (TPR), defendida explícitamente por universidades religiosamente confesionales, aunque también podrían asumirla universidades políticamente comprometidas, o gubernamentalmente intervenidas, o incluso internamente capturadas. En Chile no sólo conviven universidades puramente docentes y aun organizadas como sociedades lucrativas con otras estatales y privadas relativamente complejas, sino que además en algunas instituciones con pretensiones universitarias se hallan mayores o menores límites a la libertad de docencia y de investigación. ${ }^{11}$ Más llamativo aún es que tales limitaciones de la libertad y el pluralismo sean tan reconocidas fácticamente como alentadas normativamente. Es lo que hace la TPR, que es una tesis de iure acerca del pluralismo universitario.

${ }^{9}$ Sobre este fenómeno tan chileno, véase D. Theurillat y B. Gareca, “Organización de docencia e investigación en universidades: una exploración al caso chileno", Calidad de la Educación 42 (2015): 131-132 y 156-157.

${ }^{10}$ Es algo que podría temerse: estar ante una argumentación sustancialmente ideológica, en el preciso sentido de una mascarada que distorsiona las características del "sistema universitario" actualmente vigente en Chile y que cumple una función legitimadora del mismo.

${ }^{11}$ Este diagnóstico no es compartido por todos. Hay quienes creen que las universidades chilenas destacan en cuanto a la libertad académica y de expresión: por ejemplo A. Hax y J. Ugarte, Hacia la gran universidad chilena. Un modelo de transformación estratégica (Santiago: Ediciones UC, 2014), 26-27 y 284. 
Elaborada por académicos chilenos, ${ }^{12}$ la TPR entiende el pluralismo universitario estructural o interinstitucionalmente; vale decir, afirma que el pluralismo no tiene por qué caracterizar a todas y cada una de las universidades individualmente consideradas, pero sí al sistema de todas ellas en su conjunto. No debe sorprender que la TPR haya sido profusamente difundida por algunas instituciones con idearios religiosos como si fuese compatible con la noción moderna y contemporánea de autonomía universitaria. El problema, para decirlo desde ya, es que, abrazando un pluralismo no de cada universidad sino del agregado universitario, la TPR puede cohonestar distorsiones, aun infracciones, de la autonomía universitaria en la medida en que ésta implica libertad y pluralismo académicos. Esta TPR enarbolada preferentemente por universidades con idearios religiosos ha de ser examinada con más detalle que el empleado con la TD, pues la fundamentación filosófica argüida por aquélla es significativamente mayor que la usada por ésta.

En efecto, los valedores de la TPR se ciñen a la argumentación kantiana para caracterizar mejor sus ideas acerca de la universidad. La TPR reclama la versión kantiana de publicidad: "Publikum [es] aquel conjunto compuesto por seres humanos que, además de haber llegado a la edad adulta, son capaces de usar, por sí mismos y sin ayuda de otro, su razón de modo adulto o independiente respecto de la tutela ajena". ${ }^{13}$ Así, kantianamente, la TPR entiende que la deliberación racional no es la transacción privada - invisible a veces - de sujetos autointeresados, sino el uso público, visible, de la razón; un uso que es libre, que es recíproco y que argumenta generalizable o universalizablemente (64-65). Para la TPR, una universidad pública es una institución dispuesta “a ajustar las propias decisiones a un ejercicio libre y adulto de la razón [...lo que implica] necesariamente la disposición a dirimir las diferencias según la razón libre y no según la imposición" (67). La publicidad, por ende, no es sinónimo de estatalidad, ya que el Estado, como el poder privado, puede monopolizar peligrosamente la actividad académica

${ }^{12}$ Véase J. M. Garrido, H. Herrera y M. Svensson, La excepción universitaria. Reflexiones sobre la educación superior chilena (Santiago: UDP, 2012).

${ }^{13}$ Es cita, claro, de "Respuesta a la pregunta ¿Qué es Ilustración?" (AkademieAusgabe - Ak o Edición de la Academia de las obras de Kant- VIII, 35): véase Garrido et al., La excepción universitaria, 64. Las siguientes citas, en el cuerpo principal, se refieren a esta última obra y en cada caso se indican solamente las páginas citadas. 
y científica (63 y 68-73). Para la publicidad universitaria resulta decisiva la colaboración estatal y privada, y una colaboración interpretada como distribución (à la Montesquieu) del "poder académico y científico entre el Estado y la sociedad civil" (73-74).

Pero esto no es todo: el kantismo de la TPR es además rawlsiano. La TPR agrega que las universidades privadas pueden legítimamente -mostrando un "pluralismo real, vigoroso" (75) - asumir "concepciones comprehensivas del bien", siempre que no sean empresas lucrativas (79), que sean públicamente razonantes y que estén expuestas al escrutinio racional de la deliberación pública (74-75). Esto, que no ocurrirá sin tensiones (74), abre la posibilidad deseable de que universidades con distintos idearios se critiquen entre sí (e incluso de que en ellas haya crítica interna): "Las concepciones del bien tienen que ser lo suficientemente razonables como para poder presentarse de buena fe al escrutinio y la deliberación públicos" (74-75; ver además 76). Hablando en términos ideales, no de instituciones realmente existentes, los autores de la TPR afirman "que toda institución de educación superior es pública", si y sólo si se trata de universidades estatales o privadas que hacen uso público de la razón. En otro caso no habría sino academias constituidas "para la defensa de ciertos intereses no universalizables" (76). ${ }^{14}$

Por esto la TPR defiende no tanto la laicidad del sistema universitario (hay, de hecho, entre nosotros universidades laicas sin ideario religioso, incluso sin ideario alguno), como su interna pluralidad. ¿Consiste esto sólo en que universidades pluralistas no echarán a nadie por sus ideas? No, por supuesto; debería ser algo más. Podría decirse que en ellas ha de haber "un vivo intercambio de ideas entre quienes están profundamente enraizados en concepciones rivales de la realidad" (81). Esto último es verdaderamente excepcional, aun en universidades laicas y estatales, pues en toda universidad puede llegar a dominar cierta monotonía, cierta tendencia al monopolio de un poder económico o ideológico (81). Frente a ello, dicen, lo que necesitamos es que "la universidad sea un espacio no monopolizado por una visión de mundo" (82). Esto,

${ }^{14}$ Hay que mencionar que los autores se cuestionan si la legalidad de la publicidad razonante no admite legítimas excepciones, y si entre la reglamentación racional y la excepcionalidad de la comprensión de lo otro, de lo desconocido, no existe una tensión "posiblemente irremontable" (78). 
que podría entenderse como justificación de una necesidad de pluralismo intrínseco a cada institución universitaria (y que es calificado como una "opinión común" y "sencilla de graficar": 82), sin embargo lleva a los autores de la TPR a afirmar, como si fuese un corolario de sus tesis kantianas y rawlsianas, que la universidad no debe ser "mera reproductora académica del pluralismo fácticamente existente" (93; véase 83$).{ }^{15}$ ¿Por qué?

Porque, dicen, la universidad tiene que ser sobre todo "un agente transformador de nuestra vida en común" (83). Para lo cual parece imprescindible la existencia de instituciones con ideario y también de universidades sin ideario, ya que unas y otras contribuyen - cada cual a su manera - a la lucha intelectual entre "visiones rivales de lo que es la realidad" (84). Las universidades con idearios o cosmovisiones pueden jugar un papel en la deliberación racional de una comunidad, cosa que se volvería imposible si hubieran de reflejar el pluralismo socialmente existente. Más aún, porque se justifica su existencia por la contribución específicamente cultural-racional que prestan al pluralismo social, tales universidades podrían incluso mantener un cuerpo docente más o menos homogéneo (85). Esto no impide, sino que precisamente exige, que el Estado supervise que toda universidad esté a la altura de su promesa de libertad y autonomía académica: "El papel del Estado es, antes que dirigirlo todo, de un lado apoyar los esfuerzos múltiples, las iniciativas creadoras, también de privados honestos, involucrándose en ellas cuando sea necesario; de otro, fiscalizar eficazmente a todas las instituciones, controlar sus capacidades docentes e investigativas, velar porque en ellas exista suficiente espíritu crítico y tolerancia" (24).

La TPR, pues, supone que "el pluralismo en la sociedad estará garantizado y protegido precisamente por la existencia de perspectivas rivales que alcanzan a tener una expresión institucional, y que desde esa expresión institucional despliegan su identidad exponiéndose a su vez a la crítica" (85). La sociedad se enriquece, cree la TPR, porque de esta

15 "Las instituciones privadas representan visiones del hombre y la sociedad que, no obstante ser parcialmente diversas respecto de aquella que predomina actualmente en las universidades estatales, valoran el poder de la razón y la crítica. Su existencia es condición de mayores grados de pluralismo del sistema de educación superior y su desaparición o debilitamiento, al contrario, significarían un correlativo aumento en la concentración del poder docente y cultural en las solas manos del Estado" (22-23). 
forma va descubriendo la riqueza cosmovisiva que hay en la organización de diversas universidades, en sus variadas investigaciones, en sus disímiles políticas de contratación de profesores (85). Cabría decir aun que así se ensancharía la libertad individual (86). Pero, paradójicamente, la exigencia de que cada universidad sea internamente tan pluralista como las demás empobrecería la diversidad del sistema universitario. Lo que equivale a decir que una sociedad pluralista no es sólo la que exige pluralismo de las instituciones, sino también la que admite instituciones no (tan) pluralistas en su seno (86).

Dicho de otra manera. La sociedad requiere de universidades internamente pluralistas, en las cuales sus académicos — no faltaba másno tienen por fuerza que ser escépticos o indiferentes o neutrales, sino que podrían suscribir personalmente concepciones comprehensivas del bien sumamente contrapuestas entre sí. Pero, he aquí la esencia de la TPR, la sociedad también requiere de universidades con ideario, por ende menos diversas y más bien homogéneas. Con el añadido, claro, de que estas universidades comparativamente más uniformes sean permeables (exactamente como las pluralistas) a la crítica racional. Tales universidades con ideario y sometidas a la crítica racional existen ya en Chile. Lo que quizá no es tan claro es si existen universidades pluralistas en Chile, ya que algunas universidades laicas chilenas han vivido procesos de captura o instrumentalización ideológica o cosmovisiva (87). En todo caso, a la exigencia de pluralismo interno (que suele apoyarse en las ventajas que acarrea tanto para la investigación como para la docencia), los autores responden con una crítica del ideal de la neutralidad o indiferencia de la ciencia: tal ideal está hoy por decir lo menos en aprietos, según la filosofía contemporánea (Kuhn, MacIntyre, Gadamer, Plantinga, Clouser, entre otros) (88-90). De lo cual concluyen: "Los mismos que en un minuto hablan sobre la imposibilidad de la neutralidad, en el minuto siguiente parecen exigir de toda institución neutralidad para reconocerla como universidad, para luego dentro de las instituciones pluralistas exigir tal neutralidad también a cada individuo" (90). Esto, se apresura a añadir la TPR, no significa que la imposibilidad de la neutralidad exima de justificarse a las distintas visiones rivales acerca de la realidad. Todo lo contrario. Y por eso es que justificarse es lo que les exige el uso público de la razón muy especialmente a las universidades con ideario (90-91). De hecho, el control académico por 
pares es una forma estupenda de justificación universitaria racional, y a través del cual el diálogo entre plurales cosmovisiones va tomando cuerpo (91-92). Pues los idearios y cosmovisiones fuertes no sólo obligan, sino que también estimulan la autocrítica racional. Lo que no significa que las universidades han de someterse "a códigos de corrección política", ya que para poder ser "focos de novedad para la sociedad" deben gozar de libertad (93).

Todo hay que decirlo: los mismos promotores de la TPR, si bien repiten que no es deseable que cada universidad sea "mera reproductora académica del pluralismo fácticamente existente", vislumbran una posible contradicción entre pluralismo limitado y autonomía universitaria. Así, afirman rotundamente que "la universidad no puede ser un ghetto" (86), que es necesario que cada universidad esté expuesta a la crítica, que su concepción comprehensiva del bien esté "lo suficientemente abierta a la racionalidad pública y su vocación [sea] la de lo desconocido" (86), y por lo mismo que el profesor en ella no tenga una posición contractualmente precaria que lo someta de tal manera al dueño o controlador que éste pueda despedirlo "con facilidad cuando su libertad [la del profesor] lo lleva a sostener posiciones que incomodan [al dueño o controlador]" (99). El problema, creo, es que estas concesiones no parecen constituir una objeción para los autores de la TPR, sino solamente una precisión de la misma. Por lo cual se puede decir que para la TPR las universidades con ideario (así como académicos que nunca serán neutrales) no menguan la autonomía universitaria y hacen posible el pluralismo del conjunto. ${ }^{16}$

${ }^{16}$ Para una divulgación de esta tesis, véase J. A. Guzmán, "Diversidad en las instituciones universitarias", El Mercurio A2, 15 de junio de 2015, http://www. elmercurio.com/blogs/2015/06/15/32671/Diversidad-en-las-instituciones-universitarias.aspx. Una defensa algo más detenida de la misma ofrece el think tank Instituto de Estudios de la Sociedad: P. Ortúzar, "Universidades, pluralismo y sentido público. 6 claves para el debate" (2015): 5-10, http://www.ieschile.cl/wp-content/ uploads/2015/07/2015-07-Universidades-pluralismo-y-sentido-público.pdf.

Una nueva versión de la TPR, sobre la que volveré, es la de J. García-Huidobro y M. Svensson, "Sentido de las universidades con ideario en una sociedad pluralista", Estudios Públicos 140 (2015): 33-54. Similar aceptación de universidades privadas con idearios fuertes y, por ende, no tan pluralistas es la de Brunner y Peña, quienes piensan que las universidades estatales, justamente por su deber de resguardar y cultivar el pluralismo, han de recibir un trato preferente, aunque no exclusivo, del Estado en términos financieros: J. J. Brunner y C. Peña, "Introducción. 
4.

No es difícil notar aquí un problema que debe explicitarse: ¿es acaso compatible la TPR con el ideal moderno de universidad, según el cual tanto la filosofía como las ciencias, las artes y las humanidades (más algunos saberes técnico-profesionales), mejor que tolerar o permitir instituciones universitarias estatales o privadas internamente pluralistas, precisamente las exigen puesto que en ellas se respetan las diversidades al interior de cada disciplina y, por lo mismo, se integran tales diversidades al quehacer docente e investigador? Cabría plantear también la siguiente pregunta a la luz de la TPR: ¿es posible que una institución de educación superior, cuyos propietarios (gobiernos, iglesias, partidos políticos, empresas, etcétera) deciden y delimitan lo que se enseña y lo que se investiga a partir de sus propios intereses y agendas, cumpla con los estándares básicos de una universidad?

Como se sabe, la elaboración filosófica del ideal moderno de universidad fue obra de la Ilustración. Dado que las ideas y prácticas ilustradas llegaron a Latinoamérica y a Chile no sólo tardía sino también discontinuamente, conviene recordar algunos de sus hitos a propósito de la índole universitaria. Y conviene hacerlo especialmente por el recurso que hace la TPR al uso público kantiano de la razón, así como a la razonabilidad rawlsiana de concepciones comprehensivas del bien. Por lo demás, la defensa kantiana de una universidad ilustrada, prescindiendo de peculiaridades parcialmente superadas de su propio tiempo (incluyendo la organización medieval de las facultades universitarias), y la comprensión rawlsiana de la legítima pluralidad de cosmovisiones dentro de ciertos límites (los que, originalmente pensados para comunidades políticas, pueden ser aprovechados — previa transformación-

La dialéctica público/privado entre el medioevo y la globalización”, en El conflicto de las universidades: entre lo público y lo privado, eds. J. J. Brunner y C. Peña (Santiago: UDP, 2011), 57. Lo que, a contrario sensu, implica la legítima existencia de universidades privadas, aun con pluralismo restringido, las que también merecerían apoyo estatal, si bien no de la misma envergadura que el que debe beneficiar a las universidades del Estado. O sea, la TPR. Pues, dicen, el problema no está en un sistema universitario compuesto por universidades con idearios particulares, sino en uno solamente integrado por semejantes instituciones (57). Pareja opinión sostiene J. J. León, "El conflicto de las universidades desde una perspectiva jurídica: lo público y lo privado en el debate sobre la autonomía universitaria", en el ya citado $E l$ conflicto de las universidades, 322-329. 
para instituciones con pretensiones universitarias) son vinculantes, en algunos de sus términos, para entender el sentido y alcance del pluralismo universitario de un modo distinto al que ofrece la TPR. ${ }^{17}$ Veámoslo, si bien muy sucintamente.

En El conflicto de las facultades, Kant trató de defender a la facultad de la razón, la filosófica, tanto de los ataques de las facultades profesionales (teología, medicina, derecho) como de los ataques provenientes del gobierno. ${ }^{18}$ La libertad de pensamiento, dice, requiere la neutralidad o prescindencia estatal. La obligación política no sufre por la libertad de pensamiento, mientras que esta libertad sí que sufre encadenamientos y censuras cuando el soberano es instigado por "clérigos censuradores". ${ }^{19}$ El monarca ilustrado es el que no se decanta por una especialidad en particular, como la teológica, sino el que "cuenta con la vocación, el talento y la voluntad necesarios para propiciar los intereses de todo el estamento docente, quedando asegurado el progreso de la cultura en el campo de la ciencia contra cualquier nueva intromisión de los oscurantistas" (57; $A k$ VII, 11). Los oscurantistas (¿es necesario recordarlo?) son, tal como los dogmáticos en la Crítica de la razón pura, los enemigos de la razón pública en sentido kantiano.

La universidad es, dice Kant, una comunidad científica (de profesores o docentes públicos divididos en facultades según las distintas ramas del saber) "con cierta autonomía (dado que sobre los doctos en

${ }^{17} \mathrm{Y}$, por supuesto, de una manera también diferente a la que ofrece la TD: Kant es constante en defender a la universidad (y su libertad racional y desinteresada) de su transformación (económica, especialista y utilitaria) en un instituto meramente técnico o profesional: al respecto, véase J. Timmermann, "Kants 'Streit' und die Universität von morgen", en Kant im Streit der Fakultäten, ed. V. Gerhardt (Berlin/N. York: W. de Gruyter, 2005), 62, 69 y 79-83.

${ }^{18}$ Sobre este carácter doblemente polémico del Streitschrift, véase Timmermann, "Kants 'Streit", 78-79. Por cierto, la facultad de filosofía es otro nombre para la facultad de "artes liberales" y, por ende, se subdivide, según Kant, por una parte, en una suma de saberes "históricos" o ex datis (es decir, historia, geografía, ciencias lingüísticas, culturales y naturales) y, por otra parte, en saberes "puramente racionales" o ex principiis (matemáticas puras, filosofía pura); véase Timmermann, "Kants 'Streit'”, 71-72 y 74-76; y Brandt, Wozu noch Universitäten?, 63-71.

${ }^{19}$ Véase la propia experiencia de Kant al respecto tanto en sus palabras iniciales para El conflicto de las facultades (traducción de R. Rodríguez 49-57; Ak VII, 5-11), como en las del prólogo a la primera edición de su Religionsschrift ( $A k$ VI, 6-11). Las siguientes citas, en el cuerpo principal, identifican las páginas tanto de la traducción de Rodríguez como del original en alemán. 
cuanto tales no pueden juzgar sino ellos mismos)" (61; Ak VII, 17; las cursivas son mías), la que acoge en su seno a los mejores alumnos del sistema escolar y forma profesionales liberales (62; $A k$ VII, 17). Los profesores universitarios se diferencian de los eruditos de academias o sociedades científicas y de los aficionados al saber que viven desinstitucionalizadamente ("en el estado de naturaleza del saber": 62; $A k$ VII, 18). También se diferencian de los letrados (juristas, médicos, eclesiásticos: "negociantes o peritos del saber": 63; Ak VII, 18) que sirven un cargo público y que, en cuanto tales, "actúan como instrumentos del gobierno y en provecho propio (no precisamente en aras de las ciencias)" (62; $A k$ VII, 18), los cuales no son libres para hacer uso público de sus conocimientos y están sometidos a la respectiva facultad. Es interesante notar esto: según Kant, los letrados sólo tienen parte del poder ejecutivo en su especialidad, y no han de acaparar todo el poder legislativo ni menos han de sustraerse al poder judicial que es propio de la facultad respectiva (63; $A k$ VII, 18).

Por supuesto, lo que Kant reclama para la facultad filosófica es, visto desde nuestra época, algo de que toda facultad universitaria ha de gozar: la franquía para tratar una materia que al gobierno no le interesa sancionar (que queda confiada por ello "a la propia razón del pueblo versado en ello": 64; $A k$ VII, 19), y ser por ello "independiente de los mandatos del gobierno" (65; $A k$ VII, 19). Es por esto por lo que, si el gobierno le preguntara qué ha de estudiar, le diría: limítese "a no estorbar el progreso del conocimiento y de las ciencias, 'idéjennos hacer!'” (66 n.; $A k$ VII, 20; las cursivas son mías). La facultad inferior (ahora se diría: toda facultad universitaria) tiene el privilegio de la libertad, no para mandar, pero sí para "juzgar todo cuanto tenga que ver con los intereses científicos, es decir, con la verdad" (66; $A k$ VII, 20; las cursivas son mías). Es la facultad de la razón y “debe tener el derecho de expresarse públicamente, ya que sin ello la verdad nunca llegaría a manifestarse" (ibídem). Es inferior en cuanto para la naturaleza humana es más importante poder mandar, aunque a la vez se deba obedecer a otro, que no mandar sobre nadie, "pero ser libre" (ibídem; las cursivas son mías).

Por eso, dice Kant, a la teología, a la medicina y al derecho la facultad inferior "(...) las despoja sin miramientos de las deslumbrantes plumas prestadas por el gobierno y trata con ellas en pie de igualdad conforme al canon de la libertad" (70; Ak VII, 23; las cursivas son 
mías). En la facultad de filosofía, y con ella en la universidad entera, en cambio, las doctrinas enseñadas no proceden de la obediencia a "una orden superior" (75; $A k$ VII, 27), sino de la razón ("la capacidad de juzgar con autonomía, es decir, libremente (conforme a los principios del pensar en general)": 76; $A k$ VII, 27). Lo que implica que "la facultad de filosofía, en cuanto debe ser enteramente libre para compulsar la verdad de las doctrinas que debe admitir o simplemente albergar, tiene que ser concebida como sujeta tan sólo a la legislación de la razón y no a la del gobierno" (76; $A k$ VII, 27). De ahí que toda universidad, como tal, deba tener facultad de filosofía, pues permite controlar a las superiores (la utilidad que éstas prometen al gobierno) mediante la verdad, "condición primera y esencial del saber en general" (76; $A k$ VII, 28). Aunque arrogante, la pretensión teológica de que la filosofía sea su sierva podría admitirse a condición "de que no la despidan o le tapen la boca" (76; $A k$ VII, 28). La filosofía es libre y deja en libertad, pero trata de examinar y descubrir la verdad en cualquier disciplina (76-77; $A k$ VII, 28). Las otras facultades pueden sentir la incomodidad del examen filosófico, pero si el gobierno lo prohibiera entonces se correría el riesgo del despotismo eclesiástico, jurídico o médico (77; $A k$ VII, 28-29). ${ }^{20}$ Nótese la peligrosa tendencia despótica del oscurantismo.

Kant, por ende, puede hablar de una mala polémica entre la filosofía y las facultades superiores. Un pleito académico de las facultades superiores e inferior es ilegítimo cuando, por su contenido, el debate público está limitado, o cuando, por su forma, no se basa en argumentos, sino en astucias o amenazas (78-79; $A k$ VII, 29). Contra la tentación de eclesiásticos, médicos y jurisconsultos de volverse taumaturgos que entregan recetas módicas al pueblo y así lo seducen con llamados a la pasividad y al abandono de la propia iniciativa, el filósofo tiene que poder "oponérseles públicamente, no para derribar sus doctrinas, sino únicamente para desmentir esa fuerza mágica que el pueblo les atribuye de un modo supersticioso" (80; $A k$ VII, 31; las cursivas son mías). Y es que el pueblo quiere ser guiado, incluso embaucado por chapuceros

${ }^{20}$ Además, agrega Kant paternalistamente, las facultades pueden debatir, no con el pueblo, que entonces se sublevaría contra el gobierno, sino entre sí sus dudas y reparos, por ejemplo respecto de la legislación civil o eclesiástica, y la filosofía en tales debates intrauniversitarios puede ilustrar a los funcionarios judiciales y sanitarios encauzándolos en "la senda de la verdad" (78; $A k$ VII, 29). 
del saber, que le dicen por ejemplo que hay que creer sin examinar lo creído sino sólo cumpliendo determinadas formalidades, o que hay que cumplir con la ley civil literalmente sin examinar la intención del legislador, en ambos casos tratando de conciliar deberes e inclinaciones (81-82; Ak VII, 31-32). Por ello, este pleito ilegítimo —en el que el oscurantismo ejerce sus despóticas inclinaciones - es intolerable en la medida en que aniquila a la facultad filosófica (82; $A k$ VII, 32).

Sin embargo, dice Kant, existe una polémica necesaria y legítima. Un pleito académico de las facultades superiores e inferior es legítimo cuando se trata de las doctrinas (con sus componentes de estatutos, sentimientos y revelaciones) de las facultades superiores y que - dada su falibilidad - la filosófica debe someter a crítica racional, libre y pública (82-83; $A k$ VII, 32). Dice Kant: "La facultad inferior tiene el deber de velar porque, si bien no se diga públicamente toda la verdad, sí sea verdad todo lo que se diga y sea establecido como principio" (83; $A k$ VII, 32). Kant aclara que éste no es un pleito con el pueblo, ni con el gobierno que impone y sanciona las doctrinas de las facultades superiores, sino entre facultades, estrictamente académico, y que ha de terminar con una sentencia racional en beneficio de la verdad y en contra del afán de dominio de las facultades superiores (84-86; $A k$ VII, 33-34). Y mientras éstas son el "ala derecha del parlamento de la ciencia", la filosófica es el "ala izquierda", y su contienda — que no guerra- debe resolverse sin restricciones gubernamentales a la libertad, sino siempre y sólo con el examen de "objeciones ante los expertos" (86-87; $A k$ VII, 35-36; veáse 128; $A k$ VII, 61).

Por supuesto, estas tesis kantianas acerca de la universidad fructificaron en Alemania y fuera de Alemania. En Alemania: lo que según Kant cabe esperar de la investigación (y de la docencia) en universidades modernas es algo que a su sombra ya subrayara Fichte en 1793 ante los príncipes: "No deben entorpecer la libre investigación, deben exigirla, y no pueden exigirla sino mediante el interés que ustedes mismos muestren por ella, mediante la docilidad (Folgsamkeit) con que se obedezca (hört) sus resultados". ${ }^{21}$ Poco después, en 1810, Wilhelm von Humboldt, con ideas tributarias de las kantianas, aunque

${ }^{21}$ J. G. Fichte, "Zurückforderung der Denkfreiheit von den Fürsten Europens, die sie bisher unterdrückten", en Fichtes Werke, vol. 6: Zur Politik und Moral, ed. I. H. Fichte (Berlin: W. de Gruyter, 1971), 33. 
también haciendo suyas las tesis más liberales (en comparación con las fichteanas) de Schleiermacher, decía que en los establecimientos científicos superiores se ha de cultivar la ciencia "en el más profundo y más amplio sentido de la palabra (...), en toda su pureza", y ello bajo los principios de la soledad, la libertad y la cooperación. ${ }^{22}$ Para ello, dichos establecimientos deben estar en permanente estado de investigación, pues la ciencia nunca está perfectamente resuelta ("al contrario de la escuela, donde se enseñan y aprenden exclusivamente los conocimientos adquiridos y consagrados") (210; también 211 y 213). En los centros superiores orientados por la ciencia los profesores no existen "para" los alumnos, como ocurre en las escuelas, sino que "ambos existen para la ciencia" (210). De hecho, el investigador maduro requiere de la colaboración de jóvenes estudiantes para remediar su falta de vivacidad y sus unilateralidades, y para estimular búsquedas más comprehensivas y múltiples. El Estado ha de impulsar a estos centros y tratar de que no bajen su nivel o se vuelvan meras escuelas (210). Empero, la injerencia estatal es peligrosa, puede entorpecer la actividad científica de estos centros, desfigurar con sus medios e intervenciones el puro cultivo científico $(211 ; 213-214)$. Incluso en los propios establecimientos científicos superiores anida el riesgo de obstaculizar el cultivo científico (213). La universidad, en particular, depende casi esencialmente de la cátedra (215), vale decir, de "la libre exposición oral ante un auditorio" compuesto también por jóvenes que piensan junto con el profesor, pues la única manera de asimilar la ciencia es pensando independientemente, lo que coloca aun al joven estudiante cerca de los descubrimientos (215-216; y esto pese a que Humboldt creía que el nombramiento de los profesores universitarios, a diferencia de lo que ocurre con los miembros de las academias científicas, debía de ser de exclusiva competencia estatal: 218, dejando aparte la presencia en ellas de Privatdozenten: 219). Las universidades, como las academias, son en todo caso organizaciones libres; unas y otras "gozan de igual autonomía" (219). La misma enseñanza universitaria está vinculada con el estudio y el progreso

22 Véase W. v. Humboldt, "Sobre la organización interna y externa de los establecimientos científicos superiores en Berlín", en varios autores, La idea de la universidad en Alemania. Fichte, Schleiermacher, Humboldt, Nietzsche, De Lagarde, Weber, Scheler, Jaspers (Buenos Aires: Sudamericana, 1959): 209 y 215. Las siguientes citas pertenecen al mismo texto. 
científico; sin perjuicio de lo cual, en las universidades hay estudiosos "desligados de los deberes de la cátedra en todo o en parte" y que sólo están consagrados a la investigación (216). En la universidad, los antagonismos y las fricciones "son saludables y necesarios" para el avance de las investigaciones de cada cual y de la ciencia en general (218).

Por supuesto, esta reflexión acerca de la universidad alemana de fines del siglo XVIII y comienzos del siglo XIX llega hasta la actualidad. ${ }^{23} \mathrm{Y}$ se ha prolongado también fuera de Alemania. Ya en los siglos XVIII y XIX se consolidaron la autonomía, la libertad y el pluralismo de la universidad moderna, los que tanto influirán en otros sistemas de educación superior, como en las mejores universidades británicas y norteamericanas de investigación. Y esto pese a las notorias diferencias entre la universidad alemana, la estadounidense y la británica. De hecho, el modelo, moderno aunque en parte ya medieval, del autogobierno universitario (que es burocrático, mas de un agente principal interno como son los scholars) es el que hasta entrado el siglo XX dominó, más que en Alemania, en Oxbridge. ${ }^{24}$

${ }^{23}$ Véase en el citado varios autores, La idea de la universidad, una recopilación de textos hasta bien entrado el siglo XX. Por supuesto, el tratamiento del tema ha seguido desarrollándose. Entre 1967 y 1968, Hannah Arendt (todo un producto de la universidad alemana en el sentido humboldtiano de la expresión, que terminara afincada universitariamente en los Estados Unidos) decía que aunque la política tenga cierta afinidad con la mentira, en sus mejores momentos - los liberal-democráticos - acepta y facilita la existencia de "instituciones-amistosas-con-la-verdad", como el poder judicial, la prensa y, claro, las universidades: H. Arendt, "Verdad y política”, en Entre pasado y futuro, trad. A. Poljak (Barcelona: Península, 1996), 396-399. Después, J. Habermas también ha reivindicado, por supuesto que a su manera, la tradición universitaria alemana: "Die Idee der Universität", en varios autores, Die Idee der Universität. Versuch einer Standortbestimmung (Berlin: Springer, 1988), 139-173. Ni qué decir del ensayo-panfleto de Brandt, Wozu noch Universitäten? Para una defensa aparecida en una revista chilena del ideal humboldtiano (y kantiano) de universidad, véase E. Fernández et al., "Más allá del Estado y del mercado: universidades, libertad académica y vigencia del pensamiento de Wilhelm von Humboldt", Universum 27, n. ${ }^{\circ} 2$ (2012): 59-80.

24 Véase J. J. Brunner, "Regímenes de gobernanza universitaria: un estudio tipológico y de tendencias", en El conflicto de las universidades, 198-201. Sobre estos modelos universitarios no alemanes pero influidos por las tesis kantianas (y humboldtianas) hay una literatura abundante. Para hacerse una primera idea, ver H. Steele, "The University and Freedom. Lehrfreiheit and Lernfreiheit", Journal of Higher Education 34, n. ${ }^{\circ} 7$ (1963); R. Liebertwitz, "La libertad académica y la estabilidad en el empleo del profesorado en peligro de extinción en las universidades de EE.UU.”, trad. P. Núñez-Cortés, en La reforma laboral 2012: su impacto en la 
Sea de ello lo que fuere, queda esto: la autonomía universitaria entendida kantianamente exige libertad para la razón y su tarea crítica e ilustradora respecto de las mentalidades dogmáticas y oscurantistas. Precisamente por ello es que la actividad universitaria no puede ser solamente estatutaria sino, además, libremente racional. Un debate académico es sólo una mascarada cuando está limitado, cuando, como dice Kant, se basa no en argumentos sino en astucias o amenazas. Por el contrario, son universitariamente tolerables las disputas entre facultades con tal de que no haya restricciones gubernamentales a la libertad, en el entendido de que las objeciones de carácter académico son aquellas cuyo examen no ha de ser resuelto por autoridades, sino siempre y sólo — como dice Kant— " "ante los expertos". Dicho analógicamente: así como el Faktum de la ley moral acredita la libertad como su incognoscible condición de posibilidad, así también la facticidad de comunidades académicas plurales y organizadas para proteger (con mayor o menor éxito, se entiende) la docencia libre y la investigación crítica acredita la posibilidad del paradigma universitario. Lo que es tanto como decir que la docencia e investigación universitarias se distinguen de otras posibilidades en las cuales la docencia y la investigación no gozan de autonomía sino que están controladas ideológica o económicamente, y en las que, por lo tanto, los márgenes de diversidad disciplinaria (de profesores a contratar, de cursos a ofrecer, de investigaciones practicables, en general de preguntas que plantear) están aún severamente restringidos. Nótese que de haber sido adecuado el recurso a Kant por parte de la TPR, como si éste cohonestara las ideas de la TPR, entonces habría que haber discutido también las ideas kantianas respecto de la universidad. Pero no ha sido necesario hacerlo, pues incluso en sus propios términos el recurso a la argumentación ilustrada por parte

economía y el empleo, dir. P. Núñez-Cortés (Madrid: Dykinson, 2013), 195-214; P. Altbach, "Libertad académica: realidades y cambios en el ámbito internacional", trad. L. Godinas, Perfiles educativos. Instituto de Investigaciones sobre la Universidad y la Educación 22, n. ${ }^{\circ} 88$ (2000); S. Aly y J. Kuhn, comps., Academic Freedom. A Guide to the Literature (Wesport / London: Greenwood Press, 2000); E. Barendt, Academic Freedom and the Law (Oxford / Portland: Hart Publishing, 2010); S. Collini, What are Universities for? (UK: Penguin, 2010); J. Delfattore, Knowledge in the Making. Academic Freedom and Free Speech in America's Schools and Universities (New Haven / London: Yale University Press, 2010); R. Geiger, The History of American Higher Education. Learning and Culture from the Founding to World War II (Princeton: Princeton UP, 2015). 
de la TPR es tan parcial que esta tesis resulta inapropiada para caracterizar la autonomía, la libertad y el pluralismo de instituciones con pretensiones universitarias en condiciones modernas. Podría decirse que la TPR no es capaz de entender el sentido universitario del uso público de la razón: la universidad se evapora cuando en ella está representada solamente el ala derecha del parlamento de la ciencia, pues la actividad típicamente universitaria también requiere de su ala izquierda.

Sin embargo, esto no es todo. Igual cosa ocurre con Rawls. Los autores de la TPR acogen explícitamente unas tesis kantianas reelaboradas por Rawls, según las cuales el uso público de la razón permite tolerar doctrinas comprehensivas del bien en tanto éstas sean razonables. Injustificadamente, la TPR parece no incluir las especificaciones que adjunta Rawls a la noción de "doctrinas comprehensivas del bien". Si tales son doctrinas de lo bueno que pueden caracterizarse como razonables, entonces su razonabilidad implicará que los graves desacuerdos entre personas razonables no obstan, sino que hacen posible y aun obligatorio aceptar los elementos básicos de las repúblicas democráticas. En palabras de Rawls:

El liberalismo político parte del supuesto de que, a efectos políticos, una pluralidad de doctrinas comprehensivas razonables pero incompatibles es el resultado normal del ejercicio de la razón humana en el marco de las instituciones libres de un régimen constitucional democrático. El liberalismo político supone también que una doctrina comprehensiva razonable no rechazará los elementos esenciales de un régimen democrático. Evidentemente, una sociedad libre puede albergar también doctrinas comprehensivas irrealistas e irracionales, incluso desquiciadas. En cuyo caso, el problema consistirá en contenerlas de tal forma que no minen la unidad y la justicia de la sociedad. ${ }^{25}$

Lo decisivo, a mi modo de ver, es que lo que dice Rawls de una sociedad democrática y liberal puede decirse, mutatis mutandis, de una universidad. A condición de precisar sus límites, semejante transformación académica del léxico político rawlsiano es especialmente pertinente. Como en la pólis, en la universidad hay espacio para $-\mathrm{y}$

25 J. Rawls, El liberalismo politico, trad. A. Domènech (Barcelona: Crítica, 2013), 12. Las cursivas son mías. 
aun necesidad de - doctrinas diversas aunque razonables. Empero, si la universidad no es identificable con la comunidad política, sino que constituye una comunidad específica que pretende ser juzgada por su búsqueda y transmisión desinteresada de la verdad en la docencia y la investigación, entonces la acogida de un pluralismo tan amplio que incluya aquello que resulta ser razonable y excluya sólo aquello que resulta nítidamente irrazonable, y por ende intolerable, viene a ser la precisa medida, la verificación incluso, de la vocación por la autonomía académica de las universidades.

La investigación y la docencia universitarias penden de que las universidades, consideradas individualmente y también en su sistema, sean razonablemente libres y plurales. Si esto es así, entonces también las instituciones con ideario han de adoptar la libertad académica, so pena de no someterse a estándares genuinamente universitarios. Y lo mismo habrá que decir del pluralismo, sin el cual no tendríamos tampoco cómo distinguir entre un think tank, o un partido político, o una iglesia, o una secta, y una universidad. Lo que las universidades, en cualquier caso, no pueden aceptar, sino precisamente tienen que rechazar, son aquellas doctrinas irrazonables, "incluso desquiciadas", que en cuanto tales repugnan a una institución con pretensiones universitarias. Todo lo cual permite unos arreglos institucionales que garanticen la libertad y la constitución plural de las universidades, aun cuando estos arreglos y sus reglas jurídicas correspondientes sean precarios y estén siempre necesitados de crítica, aprendizaje y corrección. Porque si en la universidad ha de haber espacio para la investigación de punta, para los temas inexplorados, para la conceptualización de la alteridad radical y total, entonces se corre el riesgo, calificando asuntos prometedores como irrazonables e indeseables, de cerrar o inhibir su estudio y de promover en cambio algo que Kant detestaba: la censura o, también, la autocensura.

De manera que todo lo que es razonable, incluyendo cuestiones empíricas, matemáticas y humanísticas que parecen actualmente inabordables, así como también los graves desacuerdos conceptuales y normativos que existen entre personas razonables, tiene que ser no sólo tolerado sino precisamente respetado y formar parte de la docencia y la investigación de universidades propiamente tales. A contrario, sólo lo que no es razonable debe ser tratado como intolerable y quedar fuera del pluralismo universitario, siempre que a su respecto, como dice 
Rawls, se disponga "de criterios muy estrictos fundados en aspectos claros de la razonabilidad misma". ${ }^{26}$ Asimismo, lo que Rawls predica de una comunidad política - "las personas razonables pensarán que es irrazonable usar el poder político que puedan llegar a poseer para reprimir concepciones comprehensivas que no son irrazonables, por mucho que difieran de la propia" — 27 bien podría transformarse universitariamente en esto otro: las universidades simpliciter, que son las que pretenden ser tales justo porque pretenden ser públicamente razonables, son aquellas en las cuales será irrazonable usar el poder disciplinario para reprimir prácticas docentes e investigadoras que no son irrazonables, por mucho que difieran de la propia. Puede, pues, parafrasearse en sentido universitario esta otra declaración de Rawls acerca de la razón pública, para ver cuán parcial ha sido su utilización por parte de la TPR:

Puesto que hay muchas doctrinas que se consideran razonables, quienes insisten, a la hora de enfrentarse a cuestiones políticas fundamentales, en lo que ellos consideran verdadero y los demás, no, aparecen a los ojos de los demás como si insistieran en afirmar sus propias creencias cuando disponen del poder político para hacerlo. ${ }^{28}$

5.

Entonces, según esta argumentación estrictamente kantiana (y al menos parcialmente rawlsiana), la universidad pretende justificarse epistémicamente, en cuanto sostiene una relación institucionalmente

${ }^{26}$ Rawls, El liberalismo politico, 90. Las cursivas son mías.

${ }^{27}$ Ibídem, 91.

${ }^{28}$ Rawls, El liberalismo político, 92; ver 93. Sin embargo, todo hay que decirlo, en otro lugar habría que desarrollar las diferencias significativas apreciables entre las versiones que del uso público de la razón dan Kant y Rawls: mientras aquélla está gobernada por el criterio de una irrestricta universalizabilidad: "standards of reasoning that could be used to adress 'the world at large"” (O. O'Neill, "The public use of reason", en Constructions of Reason. Explorations of Kant's practical philosophy (Cambridge: Cambridge University Press, 1989), 48), ésta, en cambio, está determinada por el criterio más restringido de "una ciudadanía común al interior de una 'sociedad circunscrita', provista de una constitución democrática" (véase O. O’Neill, “Constructivismo en Rawls y Kant” Estudios Públicos 103 (2006), 413), todo lo cual también ha de tener interesantes consecuencias acerca de la razonabilidad que especifica a la institución universitaria. 
organizada entre unas comunidades rigurosas, plurales y autónomas de estudiosos, por un lado, y las mejoras del saber, por el otro. ${ }^{29}$ Lo que es tanto como decir que resulta preferible, en términos de valor epistémico, una universidad internamente pluralista a otra de pluralismo limitado, pues la universidad internamente pluralista es aquella institución que hace más probable la actividad libre de búsqueda desinteresada de la verdad - que es el horizonte de la enseñanza e investigación de ciencias, artes, humanidades, incluso de algunas técnicas y profesiones-. Todo lo cual implica la siguiente trivialidad: lo que es así fructífero para una disciplina ha de serlo también para cada universidad, en el entendido de que la universidad integra la práctica disciplinaria y no la contempla, por así decir, desde fuera, y que a esto no hace excepción la disciplina practicada y la universidad erigida con vinculaciones confesionales. Solamente desde esta perspectiva integradora cabe esperar razonablemente que el conocimiento sea cultivado con sofisticación y que la misma referencia a un mundo común de cualquier investigación y enseñanza no se vea totalmente dislocada.

Por esto es por lo que la TPR, aun en sus mejores versiones, encuentra sus problemas en su mismo "punto de arranque": mientras algunas universidades con ideario han llegado a ser "robustos espacios de apertura", otras han afectado la libertad académica y restringido el pluralismo disciplinario que deberían integrar sometiéndolo a censuras de autoridades perfectamente extrauniversitarias. Estas últimas instituciones, entonces, se han vuelto "un gueto en el cual refugiarse". 30 Dicho de otro modo, las instituciones con ideario son universidades cuando en ellas es obligatorio, y por ende está protegido, el "examen de ese lugar desde el que se mira", ${ }^{31}$ mientras que no son universidades aquellas en

${ }^{29}$ Que desde el punto de vista de la justificación epistémica las universidades se alejen del $-\mathrm{o}$ se aproximen al— procedimiento democrático es asunto que se discute: compárese, para una respuesta negativa, J. C. Bayón, “Necesita la república deliberativa una justificación epistémica?", Diritto \& Questioni Pubbliche 9 (2009); para una positiva, S. Linares, "El control de constitucionalidad: la democracia deliberativa epistémica y la dificultad contramayoritaria", Enciclopedia de filosofía y teoría del derecho, Vol. 3, eds. J. Fabra y E. Spector (México: Instituto de Investigaciones Jurídicas - UNAM, 2015), 1962-65.

${ }^{30}$ Uso los términos de García-Huidobro y Svensson, "Sentido de las universidades", 51 .

${ }^{31}$ De nuevo uso los términos de García-Huidobro y Svensson, "Sentido de las universidades", 50. 
las que no se permite ni hay lugar institucional para dicha crítica. Empero, cuando se estima "iluminador" parangonar a una universidad con un partido político (porque "a nadie se le ocurriría, en sentido estricto, exigir que un partido político sea pluralista"), ${ }^{32}$ uno no puede dejar de preguntarse si quien — pese a las diferencias — ve tales analogías entre universidades y partidos políticos está pensando propiamente en universidades o más bien en think tanks (o, por poner un ejemplo teológico, si está refiriéndose a una facultad universitaria de teología católica o musulmana, o más bien a un seminario diocesano de teología católica o a una madrasa). Porque los partidos políticos parecen más analogables con iglesias e instituciones provistas de idearios "fuertes", incluso con sectas. ${ }^{33}$ Precisamente contra el sectarismo, la pretensión socrática se ha ido desplegando no sin altibajos, pero sí como un sentido pesquisable en la actividad universitaria realmente existente - desde la edad media, pasando por la modernidad temprana, hasta llegar a estos últimos siglos- L Las universidades con idearios religiosos y sus disímiles trayectorias —ora de maneras básicamente coherentes con la docencia e investigación libres, ora de modos fundamentalmente incoherentes con éstas- constituyen en este sentido un campo de estudio de especial interés, como pusiera en evidencia Nussbaum en 1997, a propósito de una universidad católica y otra mormona en los Estados Unidos:

\section{${ }^{32}$ Ibídem, 43.}

33 Considérese desde el punto de vista universitario esta definición de cualquier institución fundamentalista en su variedad sectaria: "La forma menos ambiciosa de fundamentalismo religioso es la sectaria. Ella procura restaurar lo dado por sentado en una subcultura bajo su control, mientras que el resto de la sociedad se encuentra, por decirlo así, abandonado a manos del enemigo. Es dentro de esta subcultura donde el individuo puede encontrar el consenso social necesario para la certeza cognitiva y normativa. Ésta, por supuesto, ha sido siempre una característica de las sectas. Aun así, en una sociedad caracterizada por el pluralismo los controles sobre la interacción y la comunicación con el exterior tienen que ser, por cierto, muy rigurosos. La más leve relajación de dichos controles puede abrir una grieta en el dique protector contra la infección pluralista, y luego penetrarán definiciones alternativas de la realidad hasta inundar el interior, y la capacidad de dar las cosas por sentadas, que se mantiene precariamente, puede derrumbarse de la noche a la mañana. Por tanto, los naturalizados de la subcultura deben limitar a un mínimo el contacto con los forasteros, evitar toda conversación innecesaria, e igualmente evitar todo medio de comunicación proveniente del mundo pluralista del exterior. En otras palabras, lo que se debe establecer y mantener es una suerte de mini-totalitarismo": P. Berger, "Pluralismo global y religión", Estudios Públicos 98 (2005): $15-16$. 
Notre Dame y Brigham Young se encuentran de muchas formas en los polos opuestos de un espectro que cubre los temas relativos a la libertad académica, la indagación socrática y la diversidad en la educación superior religiosa. Sus batallas por trazar un curso que proteja tanto la identidad religiosa como la excelencia académica reflejan con precisión los desafíos a los que se ven enfrentadas muchas otras escuelas religiosas. Sobre la base de una larga tradición católica de investigación y educación superior, Notre Dame ha construido una educación auténticamente religiosa dentro de una universidad de primer orden en cuanto a investigación, con sólidas garantías de libertad académica, un decidido compromiso con la búsqueda socrática y los estudios internacionales. Los temas relativos a la mujer y la sexualidad siguen creando profundos desacuerdos, tanto en materias curriculares como en la vida universitaria; no obstante, los docentes se sienten libres de manifestar sus puntos de vista, incluso allí donde entran en conflicto con la doctrina oficial de la Iglesia. El caso de Brigham Young es el de una universidad mucho más dispuesta a restringir lo académico y la investigación en nombre de una creencia religiosa. Una actitud contraria al intelectualismo define cada vez más el curso tomado por la institución. Esta situación, en lugar de promover una institución con sólidas características religiosas, amenaza con sofocar su espíritu académico, arriesgando su condición de institución religiosa de educación superior. ${ }^{34}$

Por ello es que el sentido kantiano de la institución universitaria empalma con lo que cabría decir de la enseñanza y la investigación científica y humanística. Y es que la TPR no puede dejar de afectar los requerimientos elementales del método científico, de la práctica humanística y de la experiencia artística. Si, como dijera Kuhn, las ciencias viven momentos de normalidad (regidos por la tranquila hegemonía de un paradigma) y momentos de excepción (en los que un paradigma

${ }^{34}$ M. Nussbaum, El cultivo de la humanidad. Una defensa clásica de la reforma en la educación liberal, trad. por J. Pailaya (Barcelona: Paidós, 2005), 280-281; véase también 285, 299-300 y 327. Al respecto, el conflicto en curso entre la Pontificia Universidad Católica del Perú y el arzobispado de Lima tiene también relevancia, justo por tratarse de una universidad cuyo ideario ha llegado a ser interpretado autoritativamente de modos difícilmente compatibles con la autonomía, el pluralismo y la idea ilustrada de universidad; véase P. Quintanilla, "Catholic Universities", ReVista. Harvard Review of Latin America (otoño, 2012). 
hace crisis por la emergencia revolucionaria de otro), entonces es deseable una estructura institucional para la actividad científica y en general cognoscitiva - tanto cuando se la cultiva como cuando se la transmite- que descanse en la colaboración (aun polémica) de los diversos en pos de todo tipo de conocimiento, esto es, en la concurrencia intelectual de investigadores y estudiantes que practican el saber con la libertad que precisa todo aquel que es arrastrado por la búsqueda de la verdad, lo lleve ésta adonde lo lleve. ${ }^{35} \mathrm{Si}$ "la investigación exitosa a menudo requiere cooperación y a menudo depende crucialmente de la comunicación entre individuos", ${ }^{36}$ es porque, al menos en uno de sus sentidos,

la verdad (en relación a la realidad en general) es aquel consenso al que se llegaría finalmente en una comunidad irrestricta de investigadores si se pudiera proseguir con su proceso de investigación de forma tal que, bajo condiciones ideales comunicativas (relativas al entendimiento intersubjetivo) y epistémicas (relativas a los criterios de verdad dados en cada caso), se le hiciera avanzar críticamente - por tanto, de forma potencialmente infini$t a$ - más allá de todo consenso fáctico. ${ }^{37}$

Como es obvio, tal libertad intelectual institucionalmente garantizada - sea que se la identifique con la autonomía académica de la universidad, sea que constituya el fin de ella $-{ }^{38}$ es incompatible con la deriva sectaria (en la terminología kantiana: dogmática y oscurantista) que puede experimentar una cosmovisión, pues el sectarismo tarde o temprano termina por irritar o bloquear el estudio libre, el preguntar filosófico, el desarrollo científico, aun las tradiciones teológicas. Por el

${ }^{35}$ Ahora bien, como dijera Torretti, en el Kuhn más maduro tiende a perderse de vista la comunidad de la referencia y por ende del mundo mismo (véase R. Torretti, "Inventar para entender", Estudios filosóficos 2011-2014 (Santiago: UDP, 2014), 26-27).

${ }^{36}$ S. Haack, "La unidad de la verdad y la pluralidad de las verdades", en Teorías contemporáneas de la verdad, eds. J. A. Nicolás y M. J. Frápolli, $2^{\text {a }}$ edición (Madrid: Tecnos, 2012), 607.

${ }^{37}$ K. Apel, "Verdad como idea regulativa", en Teorías contemporáneas de la verdad, eds. Nicolás y Frápolli, 703.

${ }^{38}$ Por ejemplo, véase cómo Bernasconi, en Autonomía universitaria, distingue entre autonomía como medio y libertad académica como fin, algo que habría que examinar y discutir detalladamente, y que en todo caso este mismo autor no siempre mantiene con fidelidad. 
contrario, la universidad, cuyo núcleo es la docencia y la investigación libres, auspicia la concurrencia de puntos de vista - conviene repetirlo, tanto normales como excepcionales - , hasta tanto no se disponga de "criterios muy estrictos" acerca de lo que ya no es razonable y ha de ser expulsado de la docencia y la investigación universitaria. Si y cuando estos criterios delimitan los márgenes de lo intolerable universitariamente, no parece haber razón (generalizable) alguna para entregarlos excluyentemente a una sola doctrina comprehensiva razonable, aun cuando ésta controle o sea la dueña de una institución universitaria. Tales son no sólo las raíces kantianas, sino que también el horizonte significativo de una comprensión a la altura de los tiempos de la autonomía universitaria. Lo que equivale a decir que los compromisos universitarios de idearios religiosos o laicos (de diferentes concepciones comprehensivas del bien) son perfectamente legítimos, a condición de que sean normativa e institucionalmente mensurados a partir de una pretensión privilegiada, que no es la de la TPR por supuesto, sino la de una (siempre variada) "aristocracia del espíritu” (Aristokratie des Geistes), como dijera Weber. ${ }^{39}$

6.

Antes de terminar, conviene poner en relieve que este ideal moderno de universidad —el de la práctica libre, plural y exigente de la docencia y la investigación científica, artística, humanística y quizá de algunas técnicas y profesiones - se avistaba, con limitaciones y ambigüedades, a lo largo de la evolución de la autonomía universitaria en Chile interrumpida con el golpe militar de 1973 y que, a la inversa, la TPR se pliega a la distorsión de tal autonomía impuesta a partir de la contrarreforma universitaria pinochetista. Atria, a mi modo de ver, es quien mejor ha elaborado estos puntos. El sentido de la universidad, dice muy modernamente, consiste en ser una comunidad autónoma, autogobernada, de scholars que buscan desinteresadamente la verdad vinculando internamente a la docencia con la investigación. Por auto-

39 Véase M. Weber, "La ciencia como profesión vocacional", en varios autores, La idea de la universidad en Alemania. Fichte, Schleiermacher, Humboldt, Nietzsche, De Lagarde, Weber, Scheler, Jaspers (Buenos Aires: Sudamericana, 1959), 311. 
nomía entiende la no sujeción a poderes gubernamentales o privados y, en general, a ningún poder fáctico o interés particular. La remisión de Atria a otras tradiciones universitarias (sobre todo a la evolución universitaria alemana — con su docencia libre dependiente de la investigación libre - y norteamericana — con su superación del "modelo propietario"-) le permite ofrecer una lectura según la cual la trayectoria chilena hasta 1973 habría seguido precisamente esa misma dirección, cada vez más autónoma y menos propietaria respecto de sus controladores (Estado, partidos, iglesias, empresas, etcétera). Tal fue el sentido del Art. 10 n. ${ }^{\circ} 7$ de la Constitución de 1925 luego de la reforma de la Ley 17.398, de 1971: consagrar la autonomía académica, financiera y administrativa de las universidades tanto estatales como privadas. ${ }^{40}$

Dicha trayectoria, como es palmario, fue truncada por el golpe de Estado y la dictadura de Pinochet. Tan es así que en el Chile pospinochet la autonomía ya no es de las universidades frente al Estado y frente a sus controladores privados:

Hoy la categoría "universidad" no existe, y por eso (...) en lo que se refiere a las universidades estatales, su autonomía es una cuestión interna del derecho administrativo; en lo que se refiere a universidades privadas, su autonomía no es de ellas, sino de su dueño o controlador. El paroxismo neoliberal al que ha llegado

${ }^{40}$ Atria, Derecho sociales y educación, 283. Para una breve historia de la autonomía universitaria en Chile: véase A. Bernasconi y F. Rojas, Informe sobre la educación superior en Chile: 1980-2003 (Santiago: Universitaria, 2004), 120-126 y 195-196. Interesante notar en este último libro, primero, la afirmación de que la autonomía universitaria está limitada por la dependencia de las universidades chilenas respecto del mercado, porque después de todo no es el Estado su principal aportante de recursos, sino "los usuarios que compran sus servicios" (126). Lo que sin embargo lleva a los autores, enseguida, a malentender la autonomía como si ésta impidiera a las universidades reclamar del Estado una conducción más rigurosa y coherente del sistema universitario chileno: la exigencia por más presencia del Estado, es decir, por mayores recursos de origen estatal, puede deberse, dicen, a "una paralizante perplejidad frente a los cambios del mundo y la educación en nuestros días, una incapacidad de darle sentido al mundo [-los autores remiten aquí a un inédito de Brunner- ], y de definir una misión a la altura de estos desafíos" (126 n. 118). En el mismo sentido, aseguran que las universidades tradicionales, pese a su autonomía legal e histórica, parecen renegar de tal autonomía y esperar directivas gubernamentales que guíen el curso del sistema de educación superior, cuando en los hechos y en el derecho vigente tal orientación está en manos no estatales, sino "de las decisiones agregadas de las instituciones" (196). 
Chile se manifiesta aquí casi mejor que en cualquier otra característica del sistema jurídico chileno: el modelo institucional "propietario en sentido moral", cuyo rechazo es el punto de partida de la tradición norteamericana de autonomía universitaria, tiene en Chile rango constitucional. ${ }^{41}$

Por eso, dice Atria, es urgente una restauración de la autonomía universitaria chilena, tanto para las universidades estatales como para las privadas. En especial, urge rediseñar el estatuto del académico a partir de una libertad de cátedra e investigación no controlable por ortodoxias, ideologías o consideraciones puramente mercantiles. ${ }^{42} \mathrm{Y}$ es que en la actualidad la posición del académico y el mismo pluralismo universitario corren grave peligro:

La idea de instituciones que producen conocimiento sin estar al servicio de ninguna agenda particular, sólo por buscar la verdad, tiende a desaparecer (...). Esto no quiere decir que en los hechos los investigadores, cuando son "universitarios", sean desinteresados. Lo que quiere decir es que el estándar al que una universidad se somete, o al menos reclama estar sometida, cuando es pública y entonces no tiene una agenda parcial legítima, es el de la búsqueda desinteresada de la verdad. (...) Pero que esa institución no exista implica que ya no hay un lugar institucionalmente validado para la producción de conocimiento que se someta a sí mismo al estándar del conocimiento no interesado. (...) Es decir, hoy una universidad que se entiende al servicio de una ortodoxia religiosa puede legalmente reclamar derecho para terminar el contrato de un académico porque éste ha llegado, en su investigación, a una conclusión que es incompatible con esa ortodoxia. En el sistema universitario chileno actual, varias instituciones que se denominan universidades reclaman derecho a despedir a un académico que defienda posturas "liberales" en esas materias que la prensa denomina "valóricas": aborto, anticoncepción, homosexualidad, eutanasia, etcétera. Reclamar este derecho es algo que una uni-

${ }^{41}$ Atria, Derechos sociales y educación, 285, citando en su abono a M. Núñez, "Las universidades estatales y la construcción unitaria del principio de autonomía universitaria: ensayo de una crítica a la jurisprudencia constitucional chilena”, Estudios Constitucionales 5, n. ${ }^{\circ} 2$ (2007).

${ }^{42}$ Atria, Derechos sociales y educación, 321. 
versidad no puede hacer, por lo que la institución que lo hace no es, en rigor, una universidad. ${ }^{43}$

Para concretar esta reivindicación de la autonomía universitaria en su inmediata faceta académica, las alternativas son múltiples. En cualquiera de ellas, yo diría que es necesario tomar algunas opciones constitucionales básicas respecto de la autonomía y el pluralismo universitarios, sin que esto implique prejuzgar lo que debe decidir más detalladamente la política democrática. Por ejemplo, Atria recuerda las declaraciones que hacía la Constitución chilena de 1925 en el Art. 10 n. ${ }^{0} 7$ tal como quedara fijado en la reforma de 1971:

Las Universidades estatales y las particulares reconocidas por el Estado son personas jurídicas dotadas de autonomía académica, administrativa y económica.

Corresponde al Estado proveer a su adecuado financiamiento para que puedan cumplir sus funciones plenamente, de acuerdo a los requerimientos educacionales, científicos y culturales del país.

${ }^{43}$ Atria, Derechos sociales y educación, 300. Los casos de H. Croxato y J. Costadoat en la Pontificia Universidad Católica de Santiago de Chile, a los que pueden referirse las expresiones de Atria, son en este sentido sintomáticos y nos devuelven a las disímiles posibilidades que pueden actualizar las universidades con ideario. Véase una argumentación parecida en Académicos PUC, Declaración sobre el caso del profesor Costadoat (2015), disponible en https://academicosuc. wordpress.com/2015/03/25/declaracion-sobre-el-caso-del-profesor-costadoat/: "Nos desconcierta (...) que estemos hablando en este caso de precisamente aquella universidad, la nuestra, cuyo carácter público ha sido defendido resueltamente por nuestras autoridades en el debate ciudadano de los últimos tiempos. El carácter público de una institución dice directa relación con su condición pluralista. Y creemos que la pluralidad, otra idea intrínsecamente ligada con la de universidad, no puede darse únicamente entre distintas instituciones universitarias, sino también al interior de cada una de ellas". Así también, en C. Peña, "El caso del profesor Costadoat", El Mercurio, 29 de marzo de 2015, disponible en http://www.elmercurio. com/blogs/2015/03/29/30560/El-caso-del-profesor-Costadoat.aspx: "Nadie discute el derecho de la Iglesia a cultivar el rito, propagar su credo y contar con universidades católicas; pero esto último debe ser a condición de que se respete la índole de la universidad. No es el ethos de la universidad el que debe ceder ante los intereses de la Iglesia, sino que es la Iglesia la que debe someterse al imperativo ético que debe regir en la universidad. Si se consiente que el argumento de simple autoridad impere en la universidad, ella habrá perdido casi todo lo que la hace digna y sus académicos se habrán convertido en meros funcionarios". 
El acceso a las Universidades dependerá exclusivamente de la idoneidad de los postulantes, quienes deberán ser egresados de la enseñanza media o tener estudios equivalentes, que les permitan cumplir las exigencias objetivas de tipo académico. El ingreso y promoción de profesores e investigadores a la carrera académica se hará tomando en cuenta su capacidad y aptitudes. El personal académico es libre para desarrollar las materias conforme a sus ideas, dentro del deber de ofrecer a sus alumnos la información necesaria sobre las doctrinas y principios diversos y discrepantes. Los estudiantes universitarios tienen derecho a expresar sus propias ideas y a escoger, en cuanto sea posible, la enseñanza y tuición de los profesores que prefieran.

También, cabría recurrir a algunos de los insumos que ofrece el derecho comparado para echar luz sobre las exigencias universitarias a consagrar constitucionalmente. Un ejemplo es el brevísimo - pero luminoso- Art. 17 de la Staatsgrundgesetz austríaca de 1867: "La ciencia y su enseñanza es libre". ${ }^{44}$ Otro es el Art. 5(3) de la Grundgesetz alemana:

El arte y la ciencia, la investigación y la enseñanza científica son libres. La libertad de enseñanza no exime de la lealtad a la Constitución. ${ }^{45}$

Otro ejemplo más es el n. ${ }^{\circ} 1$ de la declaración sobre "Academic Freedom, University Autonomy and Social Responsibility" que acordara en 1998 la International Association of Universities:

El principio de la autonomía institucional puede ser definido como el necesario grado de independencia respecto de interferencia externa que la universidad requiere con respecto a su organización interna y gobierno, a la distribución interna de sus recursos financieros y la generación de recursos desde fuentes no públicas, el reclutamiento de su personal, el establecimiento de

44 "Die Wissenschaft und ihre Lehre ist frei".

45 "Kunst und Wissenschaft, Forschung und Lehre sind frei. Die Freiheit der Lehre entbindet nicht von der Treue zur Verfassung". 
las condiciones de estudio y, finalmente, la libertad de conducir enseñanza e investigación. ${ }^{46}$

Un nuevo ejemplo es la "Declaración de Guadalajara sobre autonomía universitaria” de la Unión de Universidades de América Latina y el Caribe de 2011, que entre otras cosas dice:

La autonomía universitaria es la esencia misma de la Universidad y la condición para que ésta pueda cumplir con su misión y sus responsabilidades con la sociedad (...).

La Universidad se enmarca dentro de un amplio conjunto de prerrogativas fundamentales, entre las cuales se destacan la libertad de pensamiento y la libertad de cátedra para la generación de conocimiento tendiente a la formación integral de la persona y el desarrollo democrático de la sociedad.

El Estado tiene como una de sus funciones promover el desarrollo de la sociedad y la actividad universitaria se vincula directamente con esta tarea, por lo que el Estado debe dotar de patrimonio y rentas propias a la Universidad a fin de que ésta pueda cumplir su indispensable función social.

La educación superior universitaria es un bien público que está al servicio de todos los sectores de la sociedad por tratarse de un derecho fundamental de carácter individual, institucional y social. La Universidad, a partir del ejercicio crítico, reflexivo y dialógico del pensamiento, contribuye a la institucionalidad de una sociedad libre y democrática.

El concepto de autonomía comprende el sentido de independencia en todas las funciones universitarias: en el gobierno, en la organización, en la docencia, en la investigación y en la extensión, así como la independencia del movimiento estudiantil (...).

El Estado debe asegurar y cumplir su obligación de otorgar el financiamiento necesario y expedito de las universidades.

46 "The principle of Institutional Autonomy can be defined as the necessary degree of independence from external interference that the University requires in respect of its internal organisation and governance, the internal distribution of financial resources and the generation of income from non public sources, the recruitment of its staff, the setting of the conditions of study and, finally, the freedom to conduct teaching and research". 
Asumimos el compromiso de velar colectiva, sistemática y permanentemente por la preservación y vigencia del principio de autonomía universitaria dentro y fuera de las universidades (...).

Este último ejemplo, si se lo lee con detención, no sólo provee materiales para la faz académica de la autonomía universitaria, sino también para sus facetas administrativa y financiera. ${ }^{47}$ Sea de ello lo que fuere, convendría reconfigurar esta declaración que trata a la educación superior como bien público para que incluya la idea, desarrollada por Reinhard Brandt, en orden a que hay un interés (¿un verdadero derecho?) de los ciudadanos a tener universidades con docencia e investigación libres. ${ }^{48}$ Además, la misma frase citada al final ("asumimos el compromiso de velar colectiva, sistemática y permanentemente por la preservación y vigencia del principio de autonomía universitaria”) permite colegir cuán necesaria es la coordinación de las universidades propiamente tales (esto es, de las instituciones cuyas actividades preponderantes pretenden ser la docencia y la investigación libres), lo cual incluye muy destacadamente la necesidad de que los profesores universitarios actúen de manera convergente. ${ }^{49}$

En Chile, la necesaria contestación de aquello que expresan la TD y la TPR parece haber optado por la obsesión lingüísticamente desafortunada de añadir el atributo "público" a las universidades. ${ }^{50}$ Como si la distinción entre un uso privado y uno público de la razón pudiese prolongarse para admitir unos modos privados (en el sentido de obedientes y heterónomos) y unos modos públicos (en el sentido de libres

${ }^{47}$ Lo cual requeriría una argumentación específica a desarrollar en otro lugar, una argumentación que en todo caso envuelva una crítica de las políticas y reglas institucionales que, orientadas por la New Public Management y acogidas por la TD, han asentado en Chile unas formas de financiamiento de la investigación y la docencia tan torpes, anquilosadas e insuficientes y unos modos de gobierno universitario tan "propietarios" que ponen en peligro no sólo la autonomía financiera, sino también la autonomía administrativa y las capacidades científicas de las universidades.

${ }^{48}$ Brandt, Wozu noch Universitäten?, 198-209.

${ }^{49}$ En este sentido, puede aprenderse de lo que han hecho los académicos de las universidades estadounidenses, al menos desde la Declaración de Principios de la Asociación Americana de Profesores Universitarios de 1915 (al respecto, véase Atria, Derechos sociales y educación, 274-275). ¿No convendría entre nosotros deliberar una análoga asociación, y, por supuesto, discutir una pareja declaración?

${ }^{50}$ En tal dirección marcha la argumentación del propio Atria en Derechos sociales y educación, 292-324. 
y autónomos) de universidad. Cosa que en Chile, por lo demás, está acompañada de mala conciencia, en la medida en que todo tipo de "universidades" (y no sólo aquellas cuyo afán es el conocimiento estudiado, investigado y enseñado) quieren ser y presentarse como "universidades públicas". A mi juicio, en vez de dejar en franquía esta prosecución del calificativo de públicas, mejor sería esforzarse por establecer un sistema que tan claramente como sea posible — según moldes conceptuales, reglas y esquemas institucionales - distinga entre universidades a secas y otras instituciones, sean éstas educativas, o políticas, incluso religiosas. Las universidades se definirían como institutos de educación superior, pero no de cualquier forma, sino mediante la dedicación no puramente técnico-profesional a la más sofisticada investigación y enseñanza (científica, humanista y artística) de estudiantes dotados de selectos talentos académicos. Podrían abrazar idearios religiosos y no religiosos, pero no de cualquier manera ni a cualquier precio, sino a partir de un preciso ideario educativo, que es el del conocimiento y su libre enseñanza. Cuando en una institución la docencia y la investigación no son razonablemente libres, cuando el conocimiento que se genera, enseña y aprende está sometido al interés de un negocio (o de otras actividades sólo instrumentalmente cognitivo-educativas), a las restricciones de la política profesional (o de cualquier figura del partisanismo), o al dictado de una autoridad intocable (eclesiástica o de otra laya), entonces cabría presumir — en Chile como en cualquier otro lugar - que no estamos frente a una universidad propiamente tal. Por ende, si una sana crítica de la razón transita entre el dogmatismo y el escepticismo, ${ }^{51}$ ¿no es imprescindible aceptar el sentido fundamental de las tesis kantianas en cuestiones universitarias, lo que precisamente entre nosotros implicaría al menos combatir la TD como una concepción escéptica de la universidad, la TPR como una variante dogmática de la misma, y defender en fin no tanto una concepción pública cuanto una idea paradigmática de universidad, esto es, una institución docente e investigadora cuyas pretensiones autónomas, críticas, exigentes y por añadidura públicas son incompatibles con prácticas y reglas heterónomas, sectarias, rústicas o mercantiles?

${ }^{51}$ Véase I. Kant, Kritik der reinen Vernunft —Crítica a la razón pura-A VII - A XXII y A 856 / B 884. 


\section{BIBLIOGRAFÍA}

Académicos PUC. "Declaración sobre el caso del profesor Costadoat". 2015. https://academicosuc.wordpress.com/2015/03/25/declaracion-sobre-el-casodel-profesor-costadoat/.

Altbach, P. "Libertad académica: realidades y cambios en el ámbito internacional". Traducido por L. Godinas. Perfiles Educativos 22, n. ${ }^{\circ} 88$ (2000): 6-20.

Aly, S. \& J. Kuhn, compiladores. Academic Freedom. A Guide to the Literature. Wesport - London: Greenwood Press, 2000.

Apel, K. O. "Verdad como idea regulativa". En Nicolás \& Frápolli, Teorías contemporáneas, 677-704.

Arendt, H. "Verdad y política". En Entre pasado y futuro. Traducido por A. Poljak. Barcelona: Península, 1996.

Atria, F. Derechos sociales y educación: un nuevo paradigma de lo público. Santiago: Lom, 2014.

Barendt, E. Academic Freedom and the Law. Oxford - Portland: Hart Publishing, 2010.

Barros, E. \& A. Fontaine. “Apuntes acerca de la universidad en tiempos de conflicto". Estudios Públicos 124 (2011): 139-149.

Bayón, J. C. “¿Necesita la república deliberativa una justificación epistémica?”. Diritto \& Questioni Pubbliche 9 (2009): 189-228.

Berger, P. "Pluralismo global y religión”. Estudios Públicos 98 (2005): 5-18.

Bernasconi, A. "Autonomía universitaria en el siglo XXI: nuevas formas de legitimidad ante las transformaciones del Estado y la sociedad". Páginas de Educación 7, n. ${ }^{\circ} 2$ (2014): 33-60.

— - editor. La educación superior de Chile. Transformación, desarrollo y crisis. Santiago: Ediciones UC, 2015.

—. "El gobierno de las instituciones". En La educación superior de Chile. Transformación, desarrollo y crisis, editado por A. Bernasconi, 259-293. Santiago: Ediciones UC, 2015.

- "Government and University Autonomy: The Governance Structure of Latin American Public Institutions". En Latin America's New Knowledge Economy: Higher Education, Government, and International Collaboration, editado por J. Balán, 1-17. New York: Institute for International Education, 2013.

Bernasconi, A. \& F. Rojas. Informe sobre la educación superior en Chile: 19802003. Santiago: Universitaria, 2004.

Brandt, R. Wozu noch Universitäten? Ein Essay. Hamburg: Meiner, 2011.

Brunner, J. J. “Ideas y fines de la universidad”. Estudios Públicos 139 (2015): 155164.

- "Regímenes de gobernanza universitaria: un estudio tipológico y de tendencias". En Brunner \& Peña, El conflicto de las universidades, 187-226. 
Brunner, J. J. \& C. Peña. "Introducción. La dialéctica público/privado entre el medioevo y la globalización”. En Brunner \& Peña, El conflicto de las universidades, 9-61.

— - editores. El conflicto de las universidades: entre lo público y lo privado. Santiago: UDP, 2011.

Collini, S. What are Universities for? UK: Penguin, 2010.

Delfattore, J. Knowledge in the Making. Academic Freedom and Free Speech in America's Schools and Universities. New Haven - London: Yale University Press, 2010.

Fernández, E. "Políticas públicas de educación superior desde 1990 hasta el presente". En Bernasconi, La educación superior de Chile, 173-218.

Fernández, E., G. Lenhardt, M. Stock \& R. Reisz. "Más allá del Estado y del mercado: universidades, libertad académica y vigencia del pensamiento de Wilhelm von Humboldt". Universum 27, n. ${ }^{\circ} 2$ (2012): 59-80.

Fichte, J. G. "Zurückforderung der Denkfreiheit von den Fürsten Europens, die sie bisher unterdrückten”. En Fichtes Werke, vol. 6, Zur Politik und Moral, editado por I. H. Fichte, 1-35. Berlin: W. de Gruyter, 1971.

Fontaine, A. "Contra la visión fabril de la educación: ¿Universidades con fines de lucro?”. Estudios Públicos 127 (2012): 193-217.

—_. "Lucro, universidad y filantropía”. Estudios Públicos 128 (2012): 157-173.

García-Huidobro, J. \& M. Svensson. "Sentido de las universidades con ideario en una sociedad pluralista”. Estudios Públicos 140 (2015): 33-54.

Garrido, J. M., H. Herrera \& M. Svensson. La excepción universitaria. Reflexiones sobre la educación superior chilena. Santiago: UDP, 2012.

Geiger, R. The History of American Higher Education. Learning and Culture from the Founding to World War II. Princeton: Princeton University Press, 2015.

Guzmán, J. A. "Diversidad en las instituciones universitarias". El Mercurio, A2, 15 de junio de 2015. http://www.elmercurio.com/blogs/2015/06/15/32671/ Diversidad-en-las-instituciones-universitarias.aspx.

Haack, S. "Entrevista a Susan Haack”. Traducido por C. Vázquez. Doxa 36 (2013): $585-586$.

—. "La unidad de la verdad y la pluralidad de las verdades". En Nicolás \& Frápolli, Teorías contemporáneas, 587-608.

Habermas, J. "Die Idee der Universität". En varios autores, Die Idee der Universität. Versuch einer Standortbestimmung, 139-173. Berlin: Springer, 1988.

Hax, A. \& J. J. Ugarte. Hacia la gran universidad chilena. Un modelo de transformación estratégica. Santiago: Ediciones UC, 2014.

Humboldt, W. v. "Sobre la organización interna y externa de los establecimientos científicos superiores en Berlín”. Traducción de W. Roces. En varios autores, La idea de la universidad en Alemania, 209-219.

Kant, I. El conflicto de las facultades en tres partes. Traducido por R. Rodríguez. Madrid: Alianza, 2003. 
- "Die Religion innerhalb der Grenzen der bloßen Vernunft". En Akademieausgabe von Immanuel Kants Gesammelten Werken, Vol. VI, 1-202.

—. Kritik der reinen Vernunft. Hamburg: Meiner, 1998.

Lander, E. "La ciencia neoliberal”. Tabula Rasa 9 (2008): 247-283.

León, J. J. "El conflicto de las universidades desde una perspectiva jurídica: lo público y lo privado en el debate sobre la autonomía universitaria”. En Brunner \& Peña, El conflicto de las universidades, 299-330.

Liebertwitz, R. "La libertad académica y la estabilidad en el empleo del profesorado en peligro de extinción en las universidades de EE.UU.". Traducido por P. Núñez-Cortés. En La reforma laboral 2012: su impacto en la economía y el empleo, dirigido por P. Núñez-Cortés (Madrid: Dykinson, 2013), 195-214.

Linares, S. "El control de constitucionalidad: la democracia deliberativa epistémica y la dificultad contramayoritaria". En Enciclopedia de filosofía y teoría del derecho, vol. 3, editado por J. Fabra \& E. Spector. México: Instituto de Investigaciones Jurídicas - UNAM, 2015.

Llovet, J. Adiós a la universidad. El eclipse de las humanidades. Traducido por A. Fuentes. Barcelona: Galaxia Gutenberg, 2011.

Millas, J. "La universidad: su esencia y su reforma" (1962). En Idea y defensa de la universidad (Santiago: UDP, 2012).

Morales Casetti, M. "Nueva gestión pública en Chile: orígenes y efectos". Revista de Ciencia Política 34, n. 2 (2014): 417-438.

Nicolás, J. A. \& M. J. Frápolli, editores. Teorías contemporáneas de la verdad, $2^{\mathrm{a}}$ edición. Traducido por M. Sánchez. Madrid: Tecnos, 2012.

Núñez, M. "Las universidades estatales y la construcción unitaria del principio de autonomía universitaria: ensayo de una crítica a la jurisprudencia constitucional chilena”. Estudios Constitucionales 5, n. ${ }^{\circ} 2$ (2007): 223-249.

Nussbaum, M. El cultivo de la humanidad. Una defensa clásica de la reforma en la educación liberal. Traducido por J. Pailaya. Barcelona: Paidós, 2005.

O’Neill, O. “Constructivismo en Rawls y Kant”. Traducido por M. Bruggendieck. Estudios Públicos 103 (2006): 395-418.

- "The public use of reason". En Constructions of reason. Explorations of Kant's practical philosophy, 28-50. Cambridge: Cambridge University Press, 1989.

Ortúzar, P. "Universidades, pluralismo y sentido público. 6 claves para el debate" (2015). http://www.ieschile.cl/wp-content/uploads/2015/07/2015-07Universidades-pluralismo-y-sentido-público.pdf.

Peña, C. "El caso del profesor Costadoat". El Mercurio, 29 de marzo de 2015. http://www.elmercurio.com/blogs/2015/03/29/30560/El-caso-del-profesorCostadoat.aspx.

Quintanilla, P. "Catholic Universities". ReVista. Harvard Review of Latin America (otoño, 2012). http://revista.drclas.harvard.edu/book/catholic-universities. 
Rawls, J. El liberalismo político. Traducido por A. Domènech. Barcelona: Crítica, 2013.

Rodríguez, R. "Universidad y dictadura. A propósito de la calidad universitaria". Escrituras aneconómicas 4 (2013). https://issuu.com/revista-escriturasaneconomicas/docs/escrituras_del_golpe

Steele, H. "The University and Freedom. Lehrfreiheit and Lernfreiheit". Journal of Higher Education 34, n. 7 (1963): 361-370.

Theurillat, D. \& B. Gareca. "Organización de docencia e investigación en universidades: una exploración al caso chileno". Calidad de la Educación 42 (2015): 123-160.

Timmermann, J. “Kants 'Streit' und die Universität von morgen”. En Kant im Streit der Fakultäten, editado por V. Gerhardt, 61-83. Berlin - Nueva York: W. de Gruyter, 2005.

Torretti, R. "Inventar para entender". En Estudios filosóficos 2011-2014, 11-29. Santiago: UDP, 2014.

Varios autores. La idea de la universidad en Alemania. Fichte, Schleiermacher, Humboldt, Nietzsche, De Lagarde, Weber, Scheler, Jaspers. Buenos Aires: Sudamericana, 1959.

Varios autores. Declaración de científicos chilenos: "Nuestros gobiernos han elegido la ignorancia" (2015). http://www.biologiachile.cl/2015/11/09/ nuestros-gobiernos-han-elegido-la-ignorancia/.

Weber, M. "La ciencia como profesión vocacional". Traducido por P. Heller. En varios autores, La idea de la universidad en Alemania, 305-338. EP 